\title{
Effect of silica fume on steel fiber bond characteristics in reactive powder concrete
}

\author{
Yin-Wen Chan*, Shu-Hsien Chu \\ Department of Civil Engineering, National Taiwan University, Taipei 106, Taiwan
}

Received 24 May 2002; accepted 2 December 2003

\begin{abstract}
In this paper, the effect of silica fume on the bond characteristics of steel fiber in matrix of reactive powder concrete (RPC), including bond strength, pullout energy, etc., are presented. The experimental results on steel fiber pullout test of different conditions are reported. Various silica fume contents ranging from $0 \%$ to $40 \%$ are used in the mix proportions. Fiber pullout tests are conducted to measure the bond characteristics of steel fiber from RPC matrix. It is found that the incorporation of silica fume can effectively enhance the fiber-matrix interfacial properties, especially in fiber pullout energy. It is also concluded that in terms of the bond characteristics, the optimal silica fume content is between $20 \%$ and $30 \%$, given the conditions of the experimental program. The microstructural observation confirms the findings on the interfacial-toughening mechanism drawn from the fiber pullout test results.
\end{abstract}

(C) 2004 Elsevier Ltd. All rights reserved.

Keywords: Silica fume; Microstructure; Composites; Bond strength; Pullout strength; Interfacial transition zone

\section{Introduction}

Reactive powder concrete (RPC), otherwise known as ultra-high-performance concrete, was developed through microstructural enhancement techniques for cementitious materials. As compared to ordinary cement-based materials, the primary improvements of RPC include the particle size homogeneity, porosity, and microstructures. The mechanical properties that can be achieved include the compressive strength of the range between 200 and $800 \mathrm{MPa}$, fracture energy of the range between 1200 and $40,000 \mathrm{~J} / \mathrm{m}^{2}$, and ultimate tensile strain at the order of $1 \%[1,2]$. This is generally achieved by microstructural engineering approach, including elimination of the coarse aggregates, reduction of the water-to-cementitious material, lowering of the $\mathrm{CaO}-$ $\mathrm{SiO}_{2}$ ratio by introducing the silica components, and incorporation of steel fiber reinforcement [3-5].

The reinforcing effect of steel fibers is especially critical to the mechanical properties of RPC under tension. In this research, the bond characteristics of steel fiber in RPC matrix are investigated through fiber pullout tests with the

\footnotetext{
* Corresponding author. Tel.: +886-2-2366-0547; fax: +886-2-23631558.

E-mail address: ywchan@ntu.edu.tw (Y.-W. Chan).
}

silica fume content as the primary variable of the experimental program. The great effect of silica fume on densification of the cementitious matrix comes from the enhanced particle packing density as well as from the intensive chemical reaction due to pozzolanic reaction and silica hydrate conversion.

This paper presents the experimental results of the steel fiber-matrix bond characteristics and the discussions on the influence of silica fume content in the aspects on both particle packing and chemical reaction.

\section{Experimental program}

\subsection{Materials}

The RPC considered here is prepared by the following ingredients: ASTM Type II Portland cement; fine quartz sand (approximately $150-500 \mu \mathrm{m}$ ); crushed quartz powder (approximately 5-20 $\mu \mathrm{m}$ ); undensified silica fume (approximately $0.1-0.2 \mu \mathrm{m})$; Acrylic graft-copolymer superplasticizer; and short steel fibers $(0.16 \mathrm{~mm}$ in diameter, $13 \mathrm{~mm}$ in length, and $2600 \mathrm{MPa}$ in tensile strength). The chemical compositions and physical properties of the silica fume used in this experimental program are given in Tables 1 and 2. 
Table 1

Chemical composition of silica fume

\begin{tabular}{ll}
\hline Composition & Content (\%) \\
\hline $\mathrm{SiO}_{2}$ & 90 \\
$\mathrm{Fe}_{2} \mathrm{O}_{3}$ & 1 \\
$\mathrm{Al}_{2} \mathrm{O}_{3}$ & 1 \\
$\mathrm{CaO}$ & 0.4 \\
$\mathrm{MgO}$ & 1 \\
$\mathrm{C}$ & 2 \\
$\mathrm{LOI}$ & 3 \\
\hline
\end{tabular}

The mix proportion of the RPC in weight ratio is given in Table 3. All components are mixed, cast, and vibrated in a similar sequence as conventional concrete in the laboratory. The particles and powders are first dry-mixed for $3 \mathrm{~min}$. Half of the water and superplasticizer are then added and mixed for approximately $5 \mathrm{~min}$. Subsequently, the rest of the water and superplasticizer are added and mixed. The entire mixing process takes about $15 \mathrm{~min}$ before the RPC mix is ready to cast.

\subsection{Specimens}

A dog bone shape mold is used to prepare the fiber pullout specimens. As shown in Fig. 1, the dog bone shape specimen can be divided into two halves by Section AA. Nine steel fibers are arranged evenly on Section AA, bridging the two halves of the specimen. The total length of the steel fiber is $13 \mathrm{~mm}$. To ensure that the steel fibers are fixed in one half and will be pullout from the other half, the steel fibers are bent to form hooks on one end. The half of the specimen with the hooked end is called fixed-end half, whereas the other half is called pullout half. The fibers are carefully arranged to allow an embedment length of $10 \mathrm{~mm}$ in the pullout half of the specimen.

Each pullout specimen is installed with nine steel fibers and each with $10 \mathrm{~mm}$ of embedment length for two reasons. One is to enhance the total pullout load, and the other is to eliminate the arbitrary variation in the pullout result that may occur when only a single fiber is used.

As shown in Fig. 1, there are nine steel fibers in a pullout specimen. In the preparation of pullout specimens, the steel fibers are first installed on a temporary mount with the hooked ends protruding in the fixed-end half. The matrix is then cast in the fixed-end half. The fiber installation mount is removed on the next day. The surface of Section AA on the fixed-end half is then lubricated to prevent adhesion to

Table 2

Physical properties of silica fume

\begin{tabular}{ll}
\hline Specific surface area $\left(\mathrm{m}^{2} / \mathrm{kg}\right)$ & Approximately $18,000-20,000$ \\
Specific gravity & 2.2 \\
Bulk density $\left(\mathrm{kg} / \mathrm{m}^{3}\right)$ & Approximately $250-400$ \\
Average diameter $(\mu \mathrm{m})$ & Approximately $0.1-0.2$ \\
Percent passing $45 \mu \mathrm{m}(\%)$ & Approximately $90-100$ \\
Particle shape & Spherical \\
Form & Amorphous \\
\hline
\end{tabular}

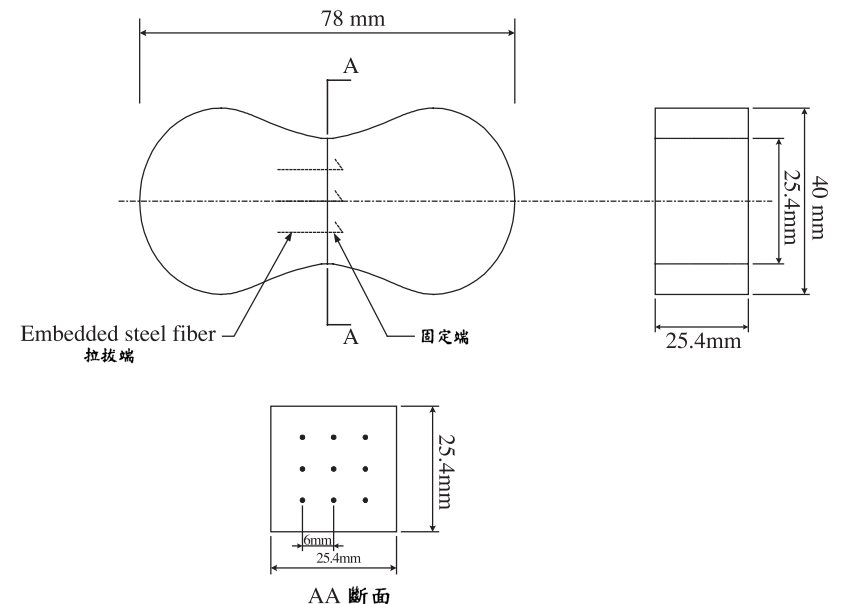

Fig. 1. Dimensions of a pullout specimen and layout of fibers.

the other half. After the treatment on the interface between the two halves, the matrix is then cast into the pullout half.

The specimen is then demolded $24 \mathrm{~h}$ after the casting of the pullout half of specimen and is cured for 3 days. The condition for curing is set constant at $85{ }^{\circ} \mathrm{C}$ and $90 \% \mathrm{RH}$. After the high-temperature curing, the specimens are kept at an environment of $20{ }^{\circ} \mathrm{C}$ and $90 \% \mathrm{RH}$ until testing. Pullout tests are conducted at the age of 7 days.

\subsection{Pullout test setup}

Fig. 2 shows the specimen fixtures and the LVDT fixtures of the pullout test setup. Two LVDTs are attached to the pullout specimen by the fixtures shown. During fiber pullout tests, the pullout load and the fiber pullout distance will be given by a loadcell and the LVDT, respectively. According to the test setup, the separation between the two halves of the specimen is regarded as the fiber pullout distance. This assumption is true when the fibers are only pulled out from the pullout half. As the embedded fibers have been anchored by the hooked ends in the fixed-end half, this hypothesis is generally valid in most cases. The

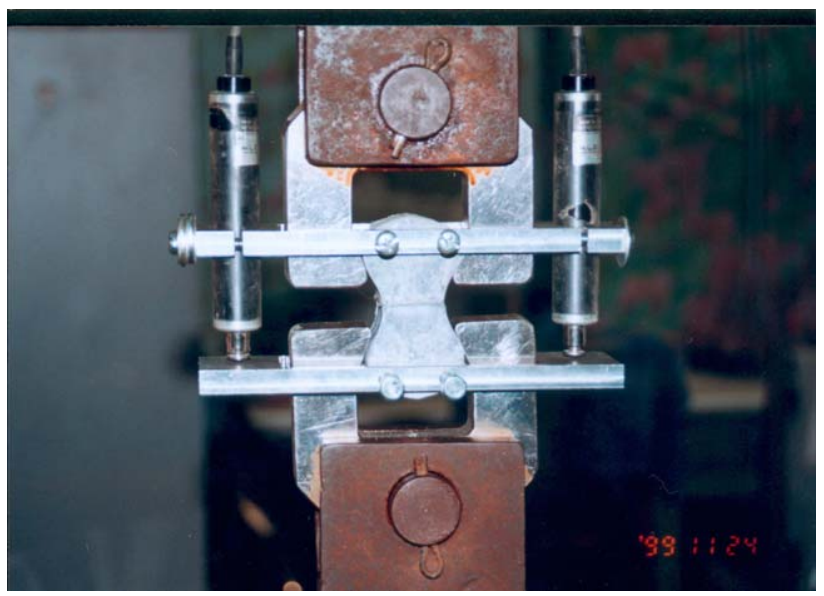

Fig. 2. Pullout test setup. 
test results will not be used for analysis if the pullout mode is not the same as mentioned. There are at least six specimens for each case.

The pullout load is estimated to be in the range of $150-$ $300 \mathrm{~N}$. The capacity of the loadcell adopted in this test is 2.5 $\mathrm{kN}$, and the resolution is $0.1 \mathrm{~N}$. The pullout test is conducted in a loading rate of $0.3 \mathrm{~mm} / \mathrm{min}$.

\section{Results and discussions}

\subsection{Fiber pullout behavior}

There is a total of four different silica fume contents used in the mix proportions of RPC for this experimental program, as given in Table 3. Six individual specimens for each case are tested. Typical fiber pullout results are given in Fig. $3 \mathrm{a}$, in which the pullout curves of RPC pullout specimens with different silica fume contents are provided. Each pullout curve is typical for that particular silica fume content. The history of pullout load is also plotted against the pullout distance in Fig. 3a.

To investigate the behavior at the stage of debonding, the pullout curves at very short pullout distances are provided in Fig. 3b. As shown in Fig. 3b, the bend-over of pullout curve from the initial branch corresponds to the debonding process of the embedded fibers. Comparing to the pullout curve with no silica fume $(0 \%)$, fibers in the matrix with various silica fume contents undergo debonding in a much lower pullout load, except the case of $20 \%$ silica fume content. After debonding, the pullout load of $0 \%$ silica fume content decreases steadily. In other words, the slip-weakening effect in this case is very significant. As can be seen in Fig. 3c, there is a significant descending branch in the pullout curve of $0 \%$ silica fume content, whereas for other cases, the pullout curves generally exhibit a plateau within the pullout distance of $1 \mathrm{~mm}$.

According to Fig. $3 \mathrm{c}$, it can be found that the steel fibermatrix interfacial properties have been altered by the incorporation of silica fume in both the debonding and pullout processes. The incorporation of silica fume in RPC matrix may result in an early debonding than the case without silica fume $(0 \%)$. After debonding, the steel fibers undergo pullout process. For the matrix with various silica fume contents, the interfacial resistance during pullout has been

Table 3

Mix proportion of RPC (weight ratio)

\begin{tabular}{lllllll}
\hline $\begin{array}{l}\text { Silica fume } \\
\text { content } \\
\text { (wt.\%) }\end{array}$ & $\begin{array}{l}\text { Type II } \\
\text { cement }\end{array}$ & $\begin{array}{l}\text { Fine } \\
\text { aggregate }\end{array}$ & $\begin{array}{l}\text { Quartz } \\
\text { powder }\end{array}$ & $\begin{array}{l}\text { Silica } \\
\text { fume }\end{array}$ & Water & Superplasticizer \\
\hline 0 & 1 & 1.25 & 0.35 & 0 & 0.3 & 0.019 \\
10 & 1 & 1.25 & 0.35 & 0.1 & 0.3 & 0.019 \\
20 & 1 & 1.25 & 0.35 & 0.2 & 0.3 & 0.019 \\
30 & 1 & 1.25 & 0.35 & 0.3 & 0.3 & 0.019 \\
40 & 1 & 1.25 & 0.35 & 0.4 & 0.3 & 0.019 \\
\hline
\end{tabular}

(a)

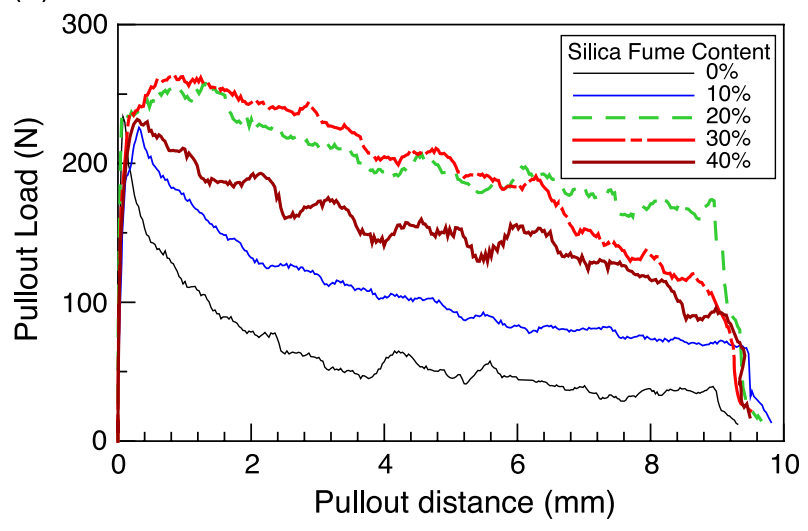

(b)

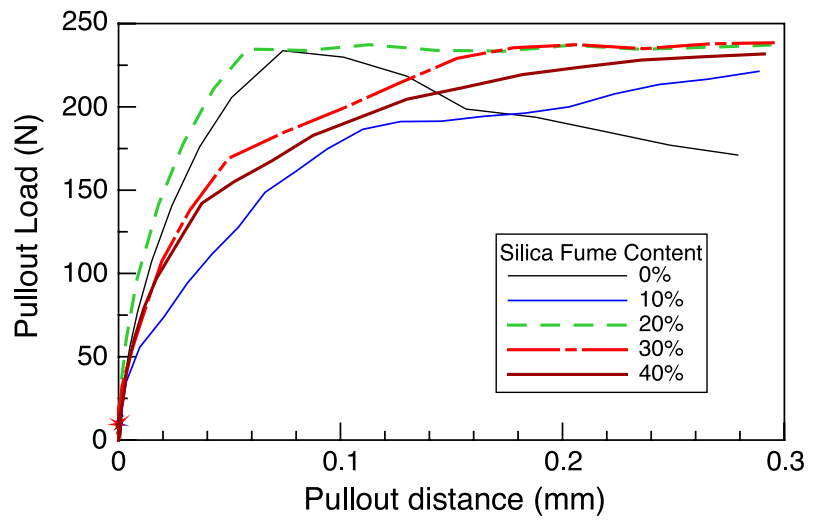

(c)

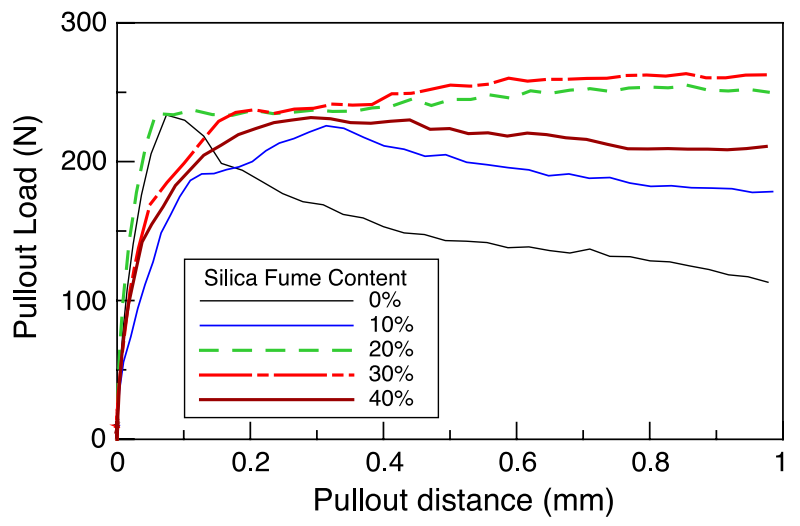

Fig. 3. Characteristics of fiber pullout curves for matrix with various silica fume contents: (a) full pullout curves; (b) pullout curves within a pullout distance of $0.3 \mathrm{~mm}$; (c) pullout curves within a pullout distance of $1.0 \mathrm{~mm}$.

toughened in different extends. It is also observed that the toughening effect is related to the silica fume content. According to Fig. 3a, the toughening effect at pullout process is the most significant in the cases with $20 \%$ and $30 \%$ of silica fume content. However, when the silica fume content keeps increasing (e.g., the case of $40 \%$ ), the interfacial-toughening effect decreases. Fig. 3a indicates that for the interfacial-toughening effect, the optimum silica fume content can be between $20 \%$ and $30 \%$. The effects of silica fume on fiber-matrix densification and on fiber bond 
Table 4

Workability of various RPC mixes

\begin{tabular}{llllll}
\hline Silica fume content (wt.\%) & 0 & 10 & 20 & 30 & 40
\end{tabular}

Flowability $(\mathrm{cm})$

$\begin{array}{lllll}>30 & >30 & 26.5 & 21.5 & 18\end{array}$

strength have been reported, including the debond mode [6] and the measured bond strength [7]. It has been found that the incorporation of silica fume has changed the fiber debond mode from strength-based to fracture-based [6], which is consistent with the interfacial-toughening mechanism observed in this experimental program as just mentioned (for the workability of the various RPC mixes, see Table 4).

\subsection{Interfacial bond strength}

The average bond strength or the maximum shear stress is defined as the following,

$\tau_{\max }=\frac{P_{\max }}{n \pi D l}$

where $\tau_{\max }$ is the bond strength or maximum shear stress; $P_{\max }$ is the maximum pullout load; $n$ is the number of embedded fibers; $D$ is the fiber diameter $(0.16 \mathrm{~mm})$; and $l$ is the embedment length of steel fiber $(10 \mathrm{~mm})$. In other words, the bond stress can be obtained from the pullout load divided by the fiber contact area. It is found that the bond stresses of various cases at full debonding are very close, which is approximately $5 \mathrm{MPa}$. However, upon further fiber pullout, the bond stresses of the matrix with various silica fume contents do not decrease significantly due to the interfacialtoughening effect. The maximum bond stresses may occur after a certain pullout distance for these cases. The bond stress of the matrix without silica fume decreases remarkably with the increase in pullout distance. In this case $(0 \%)$, the maximum bond stress occurs at full debonding.

The maximum bond stress, or the bond strength, is then interpreted and summarized in Table 5 and Fig. 4. It can be seen that the bond strength increases with the increase in silica fume content up to $30 \%$. This is consistent with the observation of the interfacial-toughening effect as just discussed. The increase in bond strength, however, is not substantial. In addition, the interfacial-toughening effect in bond strength vanishes if the silica fume content is too high, such as the case of $40 \%$.

Table 5

Bond characteristics of RPC with various silica fume contents (in the percentage of the one with $0 \%$ silica fume content)

\begin{tabular}{lccccc}
\hline Silica fume content (wt.\%) & 0 & 10 & 20 & 30 & 40 \\
Bond strength (MPa) & 4.82 & 5.00 & 5.37 & 5.48 & 4.91 \\
Increasing percentage (\%) & - & 3.8 & 11.6 & 13.8 & 2.0 \\
Pullout energy (N-mm) & 775 & 1118 & 1517 & 1543 & 1337 \\
Increasing percentage (\%) & - & 44.1 & 95.6 & 98.9 & 72.4 \\
Slope of load descending & 5.7 & 6.0 & 8.5 & 18.9 & 8.5 \\
$\quad$ N/mm) & & & & & \\
Increasing percentage (\%) & - & 5.4 & 49.7 & 232.5 & 50.3 \\
\hline
\end{tabular}

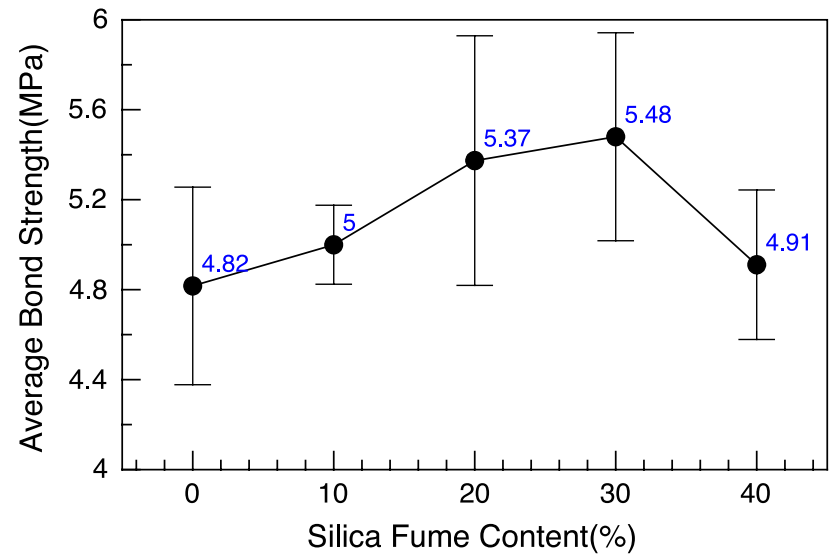

Fig. 4. Effect of silica fume on bond strength.

The average bond strength obtained in this research ranges between 4.8 and $5.5 \mathrm{MPa}$ and is comparable to that reported in Ref. [6] (3.5-4.0 MPa), which was measured using the same fiber and a less-densified cement-based matrix.

\subsection{Pullout energy}

Although the enhancement in bond strength by the incorporation of silica fume is not remarkable, the incorporation of silica fume in matrix has great effect on fiber pullout behavior in the energy aspect. The pullout energy is regarded as the mechanical energy consumed during fiber pullout process and can be obtained by integrating the area under the fiber pullout curve. In this research, the pullout energy is defined as the integration of bond stress and pullout distance based on the pullout curve up to the pullout distance of $8.5 \mathrm{~mm}$. The portion of pullout behavior beyond the pullout distance of $8.5 \mathrm{~mm}$ is excluded because of the abrupt change in the descending branch near the end of pullout process (Fig. 3a). The results are summarized in Table 6 and Fig. 5. According to Table 6, the enhancement in pullout energy due to silica fume is far more significant than that in bond strength. As compared to the matrix of no silica fume, the increase in pullout energy is nearly $100 \%$ larger than the case of $30 \%$ of silica fume. Additionally, although there is nearly no increase in bond strength, the pullout energy of the matrix of $40 \%$ of silica fume is $70 \%$ higher than that of the reference $(0 \%)$. This can be attributed to the improvement in the slip-weakening effect in the case

Table 6

Results of bond strength measurement

\begin{tabular}{|c|c|c|c|c|c|c|c|c|}
\hline \multirow{2}{*}{$\begin{array}{l}\text { Silica fume } \\
\text { content (wt.\%) }\end{array}$} & \multicolumn{6}{|c|}{ Bond strength $(\mathrm{MPa})$} & \multirow{2}{*}{$\begin{array}{l}\text { Average } \\
(\mathrm{MPa})\end{array}$} & \multirow{2}{*}{$\begin{array}{l}\mathrm{COV} \\
(\%)\end{array}$} \\
\hline & 1 & 2 & 3 & 4 & 5 & 6 & & \\
\hline & 5.50 & 4.91 & 4.51 & 5.25 & 4.40 & 4.34 & 4.82 & \\
\hline 10 & 4.70 & 5.04 & 5.15 & 5.18 & 4.92 & - & .00 & \\
\hline 20 & 5.44 & 4.68 & 5.80 & 4.93 & 6.32 & 5.07 & 5.37 & 10.3 \\
\hline 30 & 4.80 & 5.95 & 5.68 & 5.07 & 5.90 & - & 5.48 & \\
\hline 40 & 5.06 & 4.41 & 4.48 & 5.13 & 5.21 & 5.17 & 4.91 & 6.8 \\
\hline
\end{tabular}




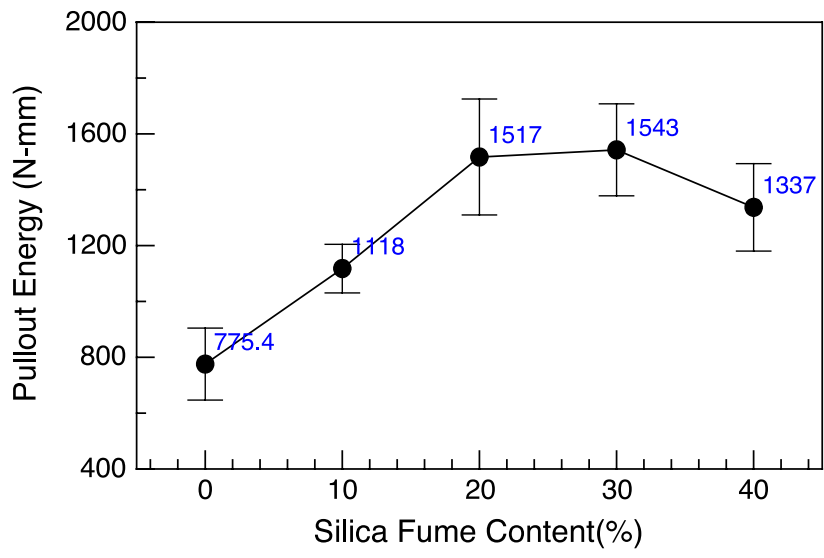

Fig. 5. Effect of silica fume on pullout energy.

of $40 \%$ of silica fume content as can be seen in the postpeak branches of pullout curves in Fig. 3a.

The pullout energy thus defined possesses a better correlation to the fracture energy of steel fiber-reinforced cement-based materials. Therefore, it is verified that the incorporation of silica fume in matrix can effectively enhance the fracture toughness of the composite materials. In terms of silica fume content, according to the results of this research, it is found that a silica fume content between 20 to $30 \%$ of cement content may offer an optimal effect.

\subsection{Interfacial microstructures}

To further investigate the interfacial-toughening mechanism by silica fume, the microstructure of fibers drawn from various types of matrix is observed. Fig. 6a shows the raw fiber surface that is not subjected to any abrasion. Fig. $6 \mathrm{~b}$ shows a fiber pulled out from the matrix without silica fume, whereas Fig. $6 \mathrm{c}$ and $\mathrm{d}$ are the surface morphology of fibers pulled out from matrix with $30 \%$ and $40 \%$ of silica fume, respectively. On the fiber surface drawn from matrix without silica fume, only longitudinal scratches can be seen, probably due to the abrasion by the matrix during pullout process (Fig. 6b). Other than those longitudinal scratches, the surface texture is very similar to that of a raw fiber as shown in Fig. 6a. On the other hand, fibers pulled out from matrix with substantial silica fume content have a dramatically different surface microstructure. As can be seen in Figs. $6 \mathrm{c}$ and $\mathrm{d}$, the fiber surface is abundant of cementitious materials that have been partially destroyed or abraded. This may help to explain the remarkably high pull out load as observed at $9 \mathrm{~mm}$ for samples with silica fume (Fig. 3a). The matrix adhering to the fiber can be worn during pullout process and may cumulate near fiber end. The cumulative matrix remnant in turn contributes to the resistance to fiber pullout load. According to the observed microstructure, the cementitious remnants on fiber surface are expected to enhance the friction and resistance. This effect may be further magnified with the increase in pullout distance. Therefore, the greatly enhanced pullout energy is believed to be a reflection of this mechanism.

Many researchers have studied the effect of silica fume on the mechanical properties of cementitious composite. The advantage in application of silica fume has been (a)

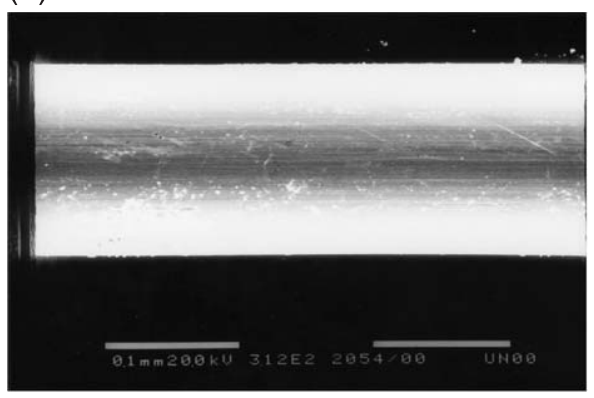

(c)

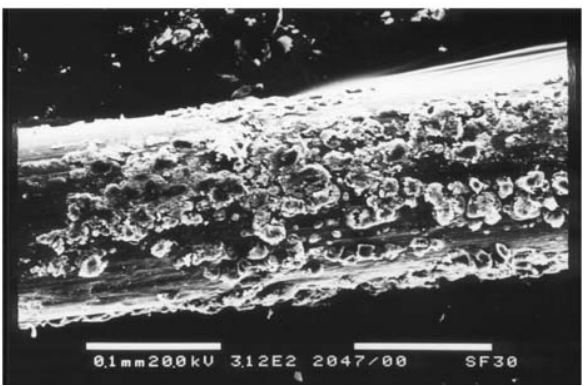

(b)

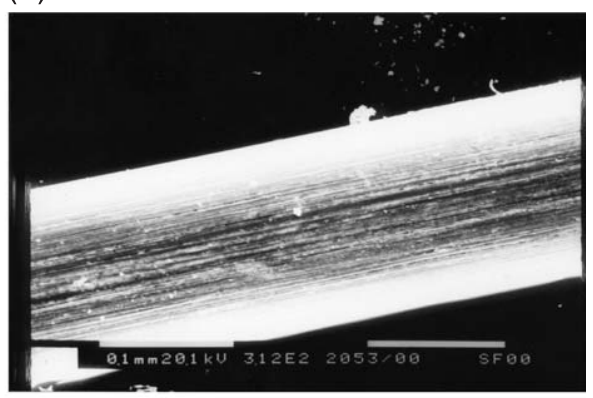

(d)

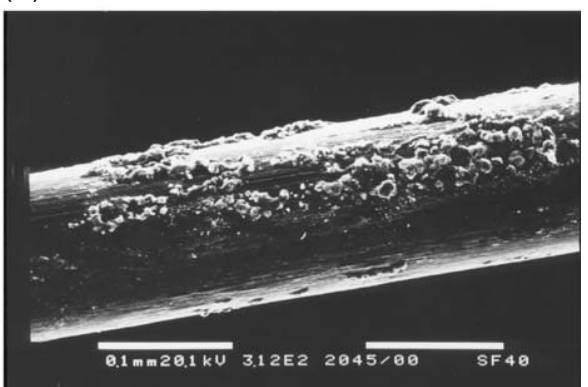

Fig. 6. SEM observation of fiber surface in various conditions $(\times 300)$ : (a) raw fiber surface; (b) pullout fiber surface ( $0 \%$ silica fume content); (c) pullout fiber surface ( $30 \%$ silica fume content); (d) pullout fiber surface ( $40 \%$ silica fume content). 
Table 7

Results of pullout energy measurement

\begin{tabular}{|c|c|c|c|c|c|c|c|c|}
\hline \multirow{2}{*}{$\begin{array}{l}\text { Silica fume } \\
\text { content (wt.\%) }\end{array}$} & \multicolumn{6}{|c|}{ Pullout energy (N-mm) } & \multirow{2}{*}{$\begin{array}{l}\text { Average } \\
(\mathrm{N}-\mathrm{mm})\end{array}$} & \multirow{2}{*}{$\begin{array}{l}\text { COV } \\
(\%)\end{array}$} \\
\hline & 1 & 2 & 3 & 4 & 5 & 6 & & \\
\hline 0 & 938 & 800 & 897 & 563 & 791 & 664 & 775 & 16.6 \\
\hline 10 & 1111 & 965 & 1178 & 1113 & 1222 & - & 1118 & 7.8 \\
\hline 20 & 1336 & 1333 & 1738 & 1484 & 1857 & 1354 & 1517 & 13.7 \\
\hline 30 & 1444 & 1723 & 1291 & 1538 & 1717 & - & 1543 & 10.7 \\
\hline 40 & 1485 & 1152 & 1106 & 1516 & 1407 & 1354 & 1337 & 11.7 \\
\hline
\end{tabular}

confirmed. In the current research, however, the fibermatrix interfacial properties are particularly concerned. The experimental results presented in this paper have verified that the incorporation of silica fume in RPC matrix can remarkably enhance the steel fiber-matrix bond characteristics, especially the interfacial-toughening effect upon fiber slip. According to the results on bond strength and pullout energy measurements (Table 7), the beneficial effect of silica fume is found to be optimal at the silica fume-cement ratio between $20 \%$ and $30 \%$, given the conditions of this experimental program. At this silica fume content, the bond strength and the fiber pullout energy are the highest one among all the cases tested. Although the increase of bond strength is not significant in the magnitude, the interfacial-toughening effect on fiber pullout is remarkable for silica fume content higher than $10 \%$. The pullout energy of the cases with silica fume content of $20 \%$ and $30 \%$ is nearly twice of the control case $(0 \%)$. This result is supported by the microstructural observation that the adhesion between steel fiber and RPC matrix with various silica fume contents is significantly improved. The finding of this research provides further understanding of the fracture mechanism of RPC. It is especially helpful if the RPC is to be further improved through microstructural engineering.

\section{Conclusions}

The experimental results presented in this paper have verified that the incorporation of silica fume in RPC matrix remarkably enhances the steel fiber-matrix bond characteristics due to the interfacial-toughening effect upon fiber slip. Specific findings of this research include the following:

1. Based on the results of bond strength and pullout energy, the optimal silica fume-cement ratio is found to be in between $20 \%$ and $30 \%$, given the conditions of this experimental program. At this silica fume dosage, the bond strength and the fiber pullout energy are the highest among all cases.

2. Comparing to that of the matrix without silica fume, the enhancement in pullout energy due to silica fume is more significant than that in bond strength. At the optimal silica fume dosage $(30 \%)$, the pullout energy is increased by approximately $100 \%$, whereas the bond strength is increased by $14 \%$. The difference can be attributed to the different mechanisms of silica fume on pullout energy and on bond strength.

3. The microstructure of fibers pulled out from high silica fume content matrix reveals a great amount of cementitious materials adhering to fiber surface. Consequently, the cementitious material contributes to the friction and resistance during the fiber pullout process. Therefore, the pullout energy is remarkably enhanced when a certain amount of silica fume content is incorporated.

\section{References}

[1] P. Richard, M. Cheyrezy, Composition of reactive powder concrete, Cem. Concr. Res. 25 (1995) 1501-1511.

[2] M.M. Reda, N.G. Shrive, J.E. Gillott, Microstructural investigation of innovative UHPC, Cem. Concr. Res. 29 (1999) 323-329.

[3] O. Bonneau, C. Vernet, M. Moranville, P.C. Aitcin, Characterization of the granular packing and percolation threshold of reactive powder concrete, Cem. Concr. Res. 30 (2000) 1861-1867.

[4] A. Feylessoufi, F.C. Tenoudji, V. Morin, P. Richard, Early ages shrinkage mechanisms of ultra-high-performance cement-based materials, Cem. Concr. Res. 31 (2001) 1573-1579.

[5] V. Matte, M. Moranville, Durability of reactive powder composites: influence of silica fume on the leaching properties of very low water/ binder pastes, Cem. Concr. Compos. 21 (1999) 1-9.

[6] V.C. Li, Y.W. Chan, Determination of interfacial debond mode for fiber reinforced cementitious composites, ASCE J. Eng. Mech. 120 (4) (1994) 707-719.

[7] Y.W. Chan, V.C. Li, Effects of transition zone densification on fiber/ cement bond strength improvement, Adv. Cem. Based Mater. 5 (1) (1997) 8-17. 